\title{
Endoscopic Endonasal Surgery for Clinically Nonfunctioning Pituitary Adenomas
}

\author{
Adel Ragab Al Melesy \\ Neurosurgery Department, Faculty of Medicine, Al-Azhar University, Cairo, Egypt \\ Email: adelalmelesy@gmail.com
}

How to cite this paper: Al Melesy, A.R. (2021) Endoscopic Endonasal Surgery for Clinically Nonfunctioning Pituitary Adenomas. Open Journal of Modern Neurosurgery, 11, 258-266. https://doi.org/10.4236/ojmn.2021.114030

Received: August 16, 2021

Accepted: October 22, 2021

Published: October 25, 2021

Copyright (อ 2021 by author(s) and Scientific Research Publishing Inc. This work is licensed under the Creative Commons Attribution International License (CC BY 4.0).

http://creativecommons.org/licenses/by/4.0/ (c) (i) Open Access

\begin{abstract}
Background: Clinically nonfunctioning pituitary adenomas (NFPAs) are the most frequent pituitary macroadenomas, and represent approximately one-third of all pituitary adenomas. Patients often present with symptoms of mass effects, such as visual field defects, chronic headache, and hypopituitarism. Objective: The objective of this study was to retrospectively analyze the surgical results of 35 patients with non-functioning pituitary adenomas (NFPAs) operated by the endoscopic endonasal approach (EEA). Surgical outcomes including postoperative complications, recurrence and the postoperative visual and endocrine profile were assessed. Results: This retrospective study included 35 patients operated for clinically nonfunctioning pituitary adenomas (NFPAs) in Al Azhar university hospitals treated by endoscopic endonasal approach (EEA) in the last 6 years. $65.7 \%(\mathrm{n}=23)$ were male and $34.3 \%(\mathrm{n}=12)$ were female. The mean age was 41.5 (range $18-65)$ years. The most common presenting symptoms were headache, with $60 \%$ of the patients having headache. Visual disturbances were the presenting symptom in 82.9\% patients and endocrinological problems (panhypopituitarism) were present in $6(17.1 \%)$ patients. The number of patients suffering from cranial nerve deficit was 2 (5.7\%). Visual acuity and visual field improved in 23 (79.3\%) of 29 patients. The rate of tumor recurrence/regrowth was higher in the case of giant adenomas and cavernous sinus invasion represented $11 \mathrm{pa}-$ tients (31.4\%). Conclusions: Early endoscopic endonasal approach surgery of NFPAs and effective surgical decompression reduces morbidity. Visual deficit improves in two third of cases. NFPAs represent high rate of recurrence due to invasion or incomplete resection especially with giant adenomas. The recurrence rate with growth total resection (GTR) is lower than subtotal resection (STR).
\end{abstract}

\section{Keywords}

Endoscopic, Nonfunctioning Pituitary Adenomas, Visual, Recurrence 


\section{Introduction}

Nonfunctioning pituitary adenomas (NFPAs) are the most common pituitary macroadenomas [1] [2] comprising $25 \%-40 \%$ of all pituitary neoplasms. Annual incidence is 1 new case per 100,000 of the population but their treatment and follow-up remains a difficult challenge [3]. Most NFPAs exhibit symptoms as a result of mass effect on adjacent structures such as the optic apparatus, the normal pituitary gland or stalk, or cranial nerves traversing the cavernous sinus [4] [5]. Endoscopic Endonasal Transsphenoidal Approach (EETA) is considered as the treatment of choice, and significant tumor debulking improves visual field disorders in $80 \%$ of patients and relieves headaches in almost every case [6]. However, even after complete or near complete surgical resection, NFMAs regrow in $12 \%-58 \%$ of patients within 5 years [7] [8].

For many years, microscopic trans-sphenoidal surgery (TSS) has been the standard of care. However, with the recent on-going advances in endoscopic visualization, endoscopic technology has been considered a major alternative [9].

At present transsphenoidal approaches are the most widely used techniques for the treatment of nonfunctioning pituitary adenomas. Suprasellar, parasellar extensions and cavernous sinus invasions of the tumors can be more effectively treated by endoscopic transsphenoidal approach that provides a better angle of vision. Previous studies have reported remission rates of $66 \%-93 \%$ for non-functioning pituitary adenomas that were treated by endoscopic transsphenoidal surgery [10] [11]. Furthermore, the rates of functional pituitary disorders have been reduced by preservation of normal pituitary gland by endoscopic techniques that have been increasingly used [12].

Limited illumination and smaller field of vision are disadvantages of the microscopic approach, whereas better illumination and visualization with a panoramic view with endoscopic approach are yet at the cost of two-dimensional images instead of three-dimensional; the latter approach allows a better extent of resection and bony exposure [13]. Endoscopic approach has better illumination and visualization with a panoramic view [14].

\section{Patients and Methods}

This study included 35 patients diagnosed with clinical NFMA (diameter $>10$ mm on computed tomography (CT) scan or sellar magnetic resonance imaging (MRI) were operated with endoscopic endonasal transsphenoidal approach at $\mathrm{Al}$ Azhar university hospitals between 2014 and 2020 included in this retrospective study.

Our objectives are assessment visual, hormonal outcome and recurrence rate of non-functionning adenomas after endoscopic endonasal surgery.

Visual acuity, fundus examination and visual field (perimetry test) investigated pre-operative and post-operative at third and six month.

Preoperative pituitary hormone measurements were investigated in all patients. The hormone panel included cortisol, prolactin, ACTH, GH, IGF-1, 
LH/FSH, fT3, fT4, TSH, estradiol, progesteron, and testosteron levels. After surgical resection of their pituitary adenomas all patients were monitored for electrolytes and hormone levels postoperatively. Serum electrolytes and urine density were measured twice a day. Anterior pituitary hormone levels were also checked the next morning after surgery and at the third month post-operative.

All patients also underwent pre-operative Pituitary Magnetic Resonance Imaging (MRI sella with dynamic contrast study) and computed tomography (CT) on brain and paranasal sinuses with bone window study. Post-surgical all subjects underwent pituitary imaging follow-up study for at 3 months after surgery to check the tumor resection volume and repeated follow up MRI study after 6 months and each year for recurrence detection. All patients underwent surgery with pure endoscopic endonasal transsphenoidal approach. Concerning the adenoma size and extension, and structural anatomy of the nasal cavity, mononostril or binostril approach was preferred. Reconstruction of skull base was performed in a multilayer manner, using free fat and fascia lata grefts taken from the lateral side of thigh, fibrin tissue adhesive, and synthetic dura grafts as needed.

\section{Results}

A total of the 35 patients operated with endoscopic endonasal transsphenoidal approach for a nonfunctioning pituitary adenoma, $65.7 \%(\mathrm{n}=23)$ were male and $34.3 \%(n=12)$ were female. The mean age was 41.5 (range $18-65)$ years.

The most common presenting symptoms were headache, with $60 \%$ of the patients having headache together with other symptoms and 51.8\% patients having headache alone. Visual disturbances were the presenting symptom in $82.9 \%$ patients and endocrinological problems (panhypopitutatrism) were present in 6 (17.1\%) patients. The number of patients suffering from cranial nerve deficit was 2 (5.7\%). Cerebrospinal fluid (CSF) leakage occurs in 5 cases representing (14.3\%) three cases of them complaining from pneumocephalaus which need early interference by secondary repair to the sellar floor. Subtotal resection (STR) was achieved in 8 cases representing (22.9\%) two cases of them presented by hematoma in the tumor bed leading to early post-operative worse visual outcome (Table 1).

Visual acuity and visual field examination (perimetry test) revealed that (17.1\%) patients had a normal visual function whereas (82.9\%) patients had decreased visual acuity in one or both eyes. Twenty-three (65.7\%) patients had visual field defects, with bitemporal hemianopsia. Visual acuity and visual field improved in $79.3 \%$ of 29 patients and $17.1 \%$ of 29 patients had no improvement with p-value (0.001), showing statically significant visual improvement post-operative as in $\mathrm{Ta}$ ble 2 and Diagram 1.

Postoperative MRI examinations of the patients operated with endoscopic endonasal approach revealed that a gross total resection was achieved in 27 (77.1\%) patients and a subtotal resection in 8 (22.9\%) (Table 3).

Five patients suffered CSF leak after the operation. Three patients complaining 
Table 1. Demographics, clinical presentation, tumor characteristics, and postoperative outcomes.

\begin{tabular}{|c|c|c|c|}
\hline & & $\mathbf{N}$ & $\%$ \\
\hline \multirow{2}{*}{ Sex } & Male & 23 & 65.7 \\
\hline & Female & 12 & 34.3 \\
\hline \multirow{4}{*}{ Clinical presentation } & Visual & 29 & 82.9 \\
\hline & Headache & 21 & 60.0 \\
\hline & Panhyporitutrism & 6 & 17.1 \\
\hline & $\mathrm{CN}$ deficit & 2 & 5.7 \\
\hline \multirow{2}{*}{ Tumor size } & Macro adenomas & 26 & 74.3 \\
\hline & Giant adenoma & 9 & 25.7 \\
\hline \multirow{3}{*}{ Visual outcome } & Stable & 4 & 11.4 \\
\hline & Improve & 23 & 65.7 \\
\hline & Worse & 2 & 5.7 \\
\hline \multirow{3}{*}{$\begin{array}{l}\text { Post-operative endocrine } \\
\text { disorders }\end{array}$} & Temporary (DI) & 4 & 11.4 \\
\hline & Permanent (DI) & 0 & 0 \\
\hline & Hypopituitarism & 6 & 17.1 \\
\hline Hematoma (Tumor bed) & & 2 & 5.7 \\
\hline C.S.F leak & & 5 & 14.3 \\
\hline Pneumocephalaus & & 3 & 8.5 \\
\hline Recurrence/regrowth & & 11 & 31.4 \\
\hline \multirow{2}{*}{ Extent of resection } & GTR & 27 & 77.1 \\
\hline & STR & 8 & 22.9 \\
\hline
\end{tabular}

D.I = Diabetes insipidus; C.S.F. $=$ Cerebrospinal fluid; GTR $=$ Growth total resection; STR $=$ Subtotal resec tion.

Table 2. Visual outcome.

\begin{tabular}{cccccc}
\hline \multirow{2}{*}{ Visual outcome } & \multicolumn{2}{c}{ Pre } & \multicolumn{3}{c}{ Post } \\
\cline { 2 - 6 } & $\mathbf{N}^{\prime}$ & $\%$ & $\mathbf{N}$ & $\%$ \\
\hline Good & 6 & 17.1 & 29 & 82.9 \\
Bad & 29 & 82.9 & 6 & 17.1 \\
Total & 35 & 100 & 35 & 100 \\
X2 & & & 30.231 & & \\
P value & & & $0.001^{*}$ & \\
\hline
\end{tabular}

Table 3. Extent of tumor resection.

\begin{tabular}{|c|c|c|c|c|c|c|c|c|c|}
\hline & & & ang & & Mean & \pm & S. D & t. test & p. value \\
\hline \multirow{2}{*}{ Age } & STR & 28 & - & 52 & 42.88 & \pm & 8.79 & \multirow{2}{*}{1.679} & \multirow{2}{*}{0.103} \\
\hline & GTR & 19 & - & 56 & 36.04 & \pm & 10.45 & & \\
\hline \multirow{2}{*}{ Tumor size } & STR & 3 & - & 6 & 4.00 & \pm & 1.20 & \multirow{2}{*}{0.984} & \multirow{2}{*}{0.332} \\
\hline & GTR & 2 & - & 6 & 3.52 & \pm & 1.22 & & \\
\hline \multirow{2}{*}{ Duration of surgery } & STR & 165 & - & 220 & 188.13 & \pm & 18.11 & \multirow{2}{*}{2.594} & \multirow{2}{*}{$0.014^{*}$} \\
\hline & GTR & 120 & - & 210 & 166.30 & \pm & 21.60 & & \\
\hline
\end{tabular}


from pneumocephalaus which need early interference by secondary repair to the sellar floor. Six patients suffer from hypopituitarism (17.1\%), three patients from the growth total resection group. The rate of tumor recurrence/regrowth was higher in case of giant adenomas and cavernous sinus invasion representing 11 patients (31.4\%) (Table 4 and Diagram 2).

Table 4. Postoperative outcome in relation to the degree of the adenoma resection.

\begin{tabular}{|c|c|c|c|c|c|c|}
\hline & & & & GTR & $\mathrm{X}^{2}$ & P-value \\
\hline \multirow{4}{*}{ Sex } & \multirow{2}{*}{ Male } & $\mathrm{N}$ & 4 & 16 & \multirow{4}{*}{0.216} & \multirow{4}{*}{0.642} \\
\hline & & $\%$ & $50.0 \%$ & $59.3 \%$ & & \\
\hline & \multirow{2}{*}{ Female } & $\mathrm{N}$ & 4 & 11 & & \\
\hline & & $\%$ & $50.0 \%$ & $40.7 \%$ & & \\
\hline \multirow{4}{*}{ Recurrence } & \multirow{2}{*}{ No } & $\mathrm{N}$ & 3 & 21 & \multirow{4}{*}{4.646} & \multirow{4}{*}{$0.031^{\star}$} \\
\hline & & $\%$ & $37.5 \%$ & $77.8 \%$ & & \\
\hline & \multirow{2}{*}{ Yes } & $\mathrm{N}$ & 5 & 6 & & \\
\hline & & $\%$ & $62.5 \%$ & $22.2 \%$ & & \\
\hline \multirow{4}{*}{ Success rate } & \multirow{2}{*}{ No } & $\mathrm{N}$ & 4 & 4 & \multirow{4}{*}{4.333} & \multirow{4}{*}{$0.037^{\star}$} \\
\hline & & $\%$ & $50.0 \%$ & $14.8 \%$ & & \\
\hline & \multirow{2}{*}{ Yes } & $\mathrm{N}$ & 4 & 23 & & \\
\hline & & $\%$ & $50.0 \%$ & $85.2 \%$ & & \\
\hline \multirow{4}{*}{ CSF leakage } & \multirow{2}{*}{ No } & $\mathrm{N}$ & 6 & 24 & \multirow{4}{*}{0.972} & \multirow{4}{*}{0.324} \\
\hline & & $\%$ & $75.0 \%$ & $88.9 \%$ & & \\
\hline & \multirow{2}{*}{ Yes } & $\mathrm{N}$ & 2 & 3 & & \\
\hline & & $\%$ & $25.0 \%$ & $11.1 \%$ & & \\
\hline \multirow{4}{*}{ Hypopituitarism } & \multirow{2}{*}{ No } & $\mathrm{N}$ & 5 & 24 & \multirow{4}{*}{3.026} & \multirow{4}{*}{0.082} \\
\hline & & $\%$ & $62.5 \%$ & $88.9 \%$ & & \\
\hline & \multirow{2}{*}{ Yes } & $\mathrm{N}$ & 3 & 3 & & \\
\hline & & $\%$ & $37.5 \%$ & $11.1 \%$ & & \\
\hline
\end{tabular}

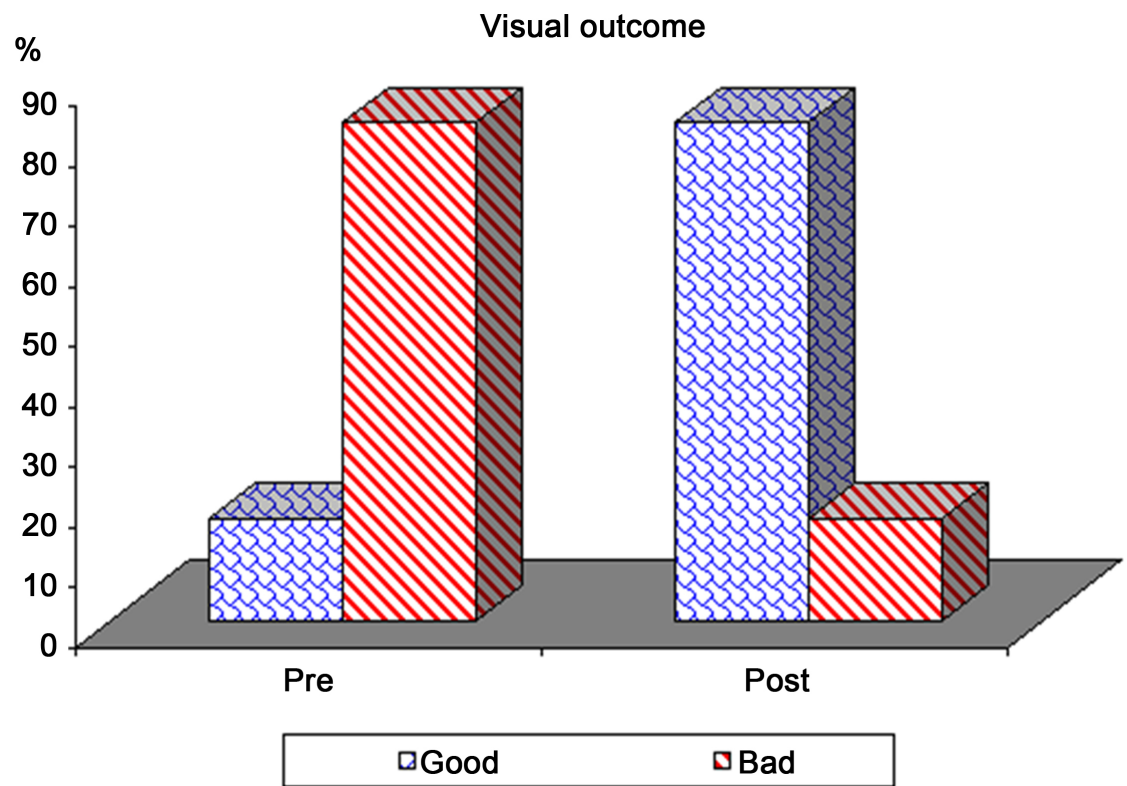

Diagram 1. Pre- and post-operative visual outcome. 


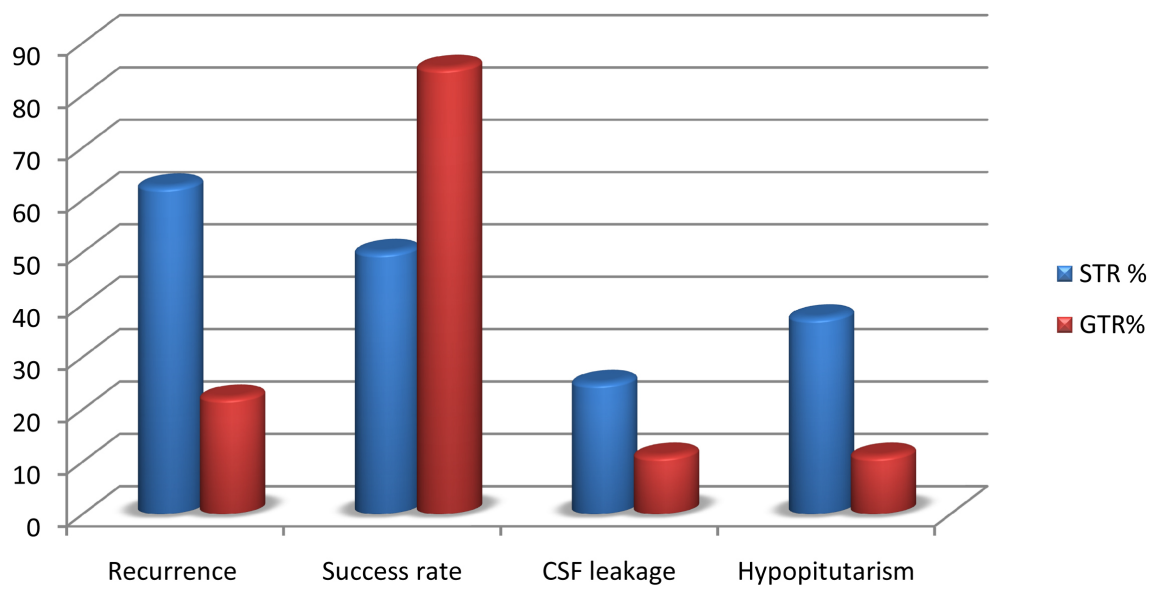

Diagram 2. Comparison between subtotal and growth total resection in post-operative outcome. C.S.F. $=$ Cerebrospinal fluid, GTR $=$ Growth total resection, STR $=$ Subtotal resection.

\section{Discussion}

In the near past non-functioning pituitary adenomas were considered as poorly treatable disease, but nowadays considered as treatable disease with applying novel surgical approaches, and improved medical and radiotherapies. In this series of 35 surgically treated NFPAs patients by endoscopic endonasal approach (EEA), with follow-up periods ranging from 3 to 60 months after surgery. 65.7\% $(\mathrm{n}=23)$ were male and $34.3 \%(\mathrm{n}=12)$ were female. The mean age was 41.5 (range 18 - 65) years. The rate of tumor recurrence/regrowth was higher in the case of giant adenomas and cavernous sinus invasion representing 11 patients (31.4\%). Venkatram Subramanian et al. [15] reported five-year recurrence-free survival after transsphenoidal resection for NFPAs was $71.5 \%$ in a series of 105 cases with mean (SD) age 60.1 (14.3) years and follow-up duration of 60 months were studied. 67 (64\%) patients were male. The low recurrent rate in our study related to the use of endoscopic approach which gross total resection can achieve in most cases rather than other microscopic approaches.

In our series growth total resection were achieved in 27 (77.1\%) with recurrence rate $6(22.2 \%)$ cases and subtotal resection were 8 cases $(22.9 \%)$ with recurrence rate 5. These results agree with Mina M. et al. In a study of 190 patients with a mean age of $63.8 \pm 13.2$ years; $79(41.6 \%)$ were female. The follow-up period was 10 years. GTR was achieved in $127(66.8 \%)$ patients. and recurrence rate at 5 and 10 years was $21 \%$ and $24.5 \%$, respectively.

The clinical characteristics of our patients are similar to those reported in other studies Dekkers et al. and Karavitaki et al. Presenting symptoms and signs were mainly related to mass effects of the tumor, leading to visual field disorders, headache, and pituitary deficiencies (hypopituitarism). We observed headache in $60 \%$ of the patients with macroadenoma. All patients were also examined for visual acuity and visual field during the preoperative period. $17.1 \%$ had normal visual examination and $82.9 \%$ had some visual problems. It was of note that a 
quarter of the patients with visual field defects were not aware of their condition. We observed a postoperative improvement in $79.3 \%$ of patients who had visual disturbances preoperative. These results agree with Mina M. et al. in study including 190 patients with headache 79 (41.6\%) and visual affection 119 (62\%).

Nonfunctioning pituitary adenomas also cause hormone deficits related to pituitary dysfunction. They give rise to symptoms not secondary to hormone hypersecretion, but rather to hormone deficiency. Some studies have reported that patients with non-functioning pituitary adenomas usually also have hormonal deficits at the time of diagnosis Drange et al. and Greenman et al. However, Messerer et al. reported a prevalence of $36 \%$ for hormone deficits. In our study, the percent of patients presenting with endocrinological symptoms secondary to hormonal dysfunction was $14 \%$.

5.7\% patients were with panhypopituitarism and 8.5\% patients with hypogonadism. Despite a greater risk of bleeding and infarction with larger adenomas, it is not correct to correlate the risk of pituitary apoplexy to adenoma size in macroadenomas or larger adenomas. Although most nonfunctioning pituitary adenomas are macroadenomas or larger, their risk of apoplexy is not as great as feared, as reported by previous studies. Nomikos et al. reported a pituitary apoplexy rate of $3.7 \%$. Despite its low incidence, pituitary apoplexy is a condition of high morbidity in terms of hormonal deficiencies and visual disturbances. In our series, 2 patients had apoplexy. One of them had clinical apoplexy and the other had subclinical apoplexy occurring as a result of intralesional bleeding and/or infarction detected by radiological imaging. Although non-functioning pituitary adenomas are silent masses due to lack of any hormone secretion, they may be considered a complex disease creating visual disturbances, hormonal deficiencies, or prolactin elevation by its compression of pituitary stalk. NFPAs require cooperation between neurosurgery, radiology, ophthalmology, and endocrinology departments, although endoscopic endonasal approach surgery is currently the accepted therapy for non-functioning pituitary adenomas. And there was a likelihood of Karavitaki et al. found that an early and effective surgical decompression reduces morbidity, and hypopituitarism occurrence of $2.4 \%$ per year in adenomas followed clinically without surgery. With observed de-novo or deteriorating visual problems in $67 \%$ of nonfunctioning pituitary adenoma cases followed clinically without surgery [16].

\section{Conclusion}

Non-functioning pituitary adenomas are a challenge due to absent clinically hormonal manifestation and patient's later start to complain of visual problems in addition to headache. Early endoscopic endonasal approach surgery of NFPAs and effective surgical decompression reduces morbidity. Visual deficit improves in two third of cases. NFPAs represent high rate of recurrence due to invasion or incomplete resection especially with giant adenomas. The recurrence rate with growth total resection (GTR) is lower than subtotal resection (STR). 


\section{Conflicts of Interest}

None.

\section{References}

[1] Chanson, P. and Brochier, S. (2005) Non-Functioning Pituitary Adenomas. Journal of Endocrinological Investigation, 28, 93-99.

[2] Greenman, Y. and Stern, N. (2009) Non-Functioning Pituitary Adenomas. Best Practice and Research Clinical Endocrinology and Metabolism, 23, 625-638. https://doi.org/10.1016/j.beem.2009.05.005

[3] Raappana, A., Koivukangas, J., Ebeling, T. and Pirila, T. (2010) Incidence of Pituitary Adenomas in Northern Finland in 1992-2007. Journal of Clinical Endocrinology \& Metabolism, 95, 4268-4275. https://doi.org/10.1210/jc.2010-0537

[4] Molitch, M.E. (2008) Nonfunctioning Pituitary Tumors and Pituitary Incidentalomas. Endocrinology and Metabolism Clinics of North America, 37, 151-171. https://doi.org/10.1016/j.ecl.2007.10.011

[5] Dekkers, O.M., Pereira, A.M. and Romijn, J.A. (2008) Treatment and Follow-Up of Clinically Nonfunctioning Pituitary Macroadenomas. Journal of Clinical Endocrinology \& Metabolism, 93, 3717-3726. https://doi.org/10.1210/jc.2008-0643

[6] Mortini, P., Barzaghi, R., Losa, M., Boari, N. and Giovanelli, M. (2007) Surgical Treatment of Giant Pituitary Adenomas: Strategies and Results in a Series of 95 Consecutive Patients. Neurosurgery, 60, 993-1002; Discussion 1003-1004. https://doi.org/10.1227/01.NEU.0000255459.14764.BA

[7] Ferrante, E., Ferraroni, M., Castrignano, T., Menicatti, L., Anagni, M., Reimondo, G., et al. (2006) Non-Functioning Pituitary Adenoma Database: A Useful Resource to Improve the Clinical Management of Pituitary Tumors. European Journal of Endocrinology, 155, 823-829. https://doi.org/10.1530/eje.1.02298

[8] O’Sullivan, E.P., Woods, C., Glynn, N., Behan, L.A., Crowley, R., O’Kelly, P., Smith, D., Thompson, C.J. and Agha, A. (2009) The Natural History of Surgically Treated but Radiotherapy-Naive Nonfunctioning Pituitary Adenomas. Clinical Endocrinology, 71, 709-714. https://doi.org/10.1111/j.1365-2265.2009.03583.x

[9] Laws, E.R. and Barkhoudarian, G. (2014) The Transition from Microscopic to Endoscopic Transsphenoidal Surgery: The Experience at Brigham and Women's Hospital. World Neurosurgery, 82, S152-S154.

https://doi.org/10.1016/j.wneu.2014.07.035

[10] Drange, M.R., Fram, N.R., Herman-Bonert, V. and Melmed, S. (2000) Pituitary Tumour Registry: A Novel Clinical Resource. Journal of Clinical Endocrinology \& Metabolism, 85, 168-174. https://doi.org/10.1210/jc.85.1.168

[11] Greenman, Y., Ouaknine, G., Veshchev, I., Reider-Groswasser, I.I., Segev, Y. and Stem, N. (2003) Postoperative Surveillance of Clinically Nonfunctioning Pituitary Macroadenomas: Markers of Tumour Quiescence and Regrowth. Clinical Endocrinology, 58, 763-769. https://doi.org/10.1046/j.1365-2265.2003.01784.x

[12] Karavitaki, N., Collison, K., Halliday, J., Byrne, J.V., Price, P., Cudlip, S. and Wass, J.A. (2007) What Is the Natural History of Nonoperated Nonfunctioning Pituitary Adenomas? Clinical Endocrinology, 67, 938-943. https://doi.org/10.1111/j.1365-2265.2007.02990.x

[13] Messerera, M., Dubourgb, J., Raverotb, G., Bervinia, D., Berhouma, M., Georgef, I., Chackof, A.G., et al. (2013) Nonfunctioning Pituitary Macro-Incidentalomas Benefit from Early Surgery before Becoming Symptomatic. Clinical Neurology and Neu- 
rosurgery, 115, 2514-2520. https://doi.org/10.1016/j.clineuro.2013.10.007

[14] Nomikos, P., Ladar, C., Fahlbusch, R. and Buchfelder, M. (2004) Impact of Primary Surgery on Pituitary Function in Patients with Non-Functioning Pituitary Adenomas-A Study on 721 Patients. Acta Neurochirurgica, 146, 27-35.

https://doi.org/10.1007/s00701-003-0174-3

[15] Subramanian, V., Lee, R.S.M., Howell, S., Gregson, S. and Kaushal, K. (2021) Non-Functioning Pituitary Macroadenomas: Factors Affecting Postoperative Recurrence, and Pre- and Post-Surgical Endocrine and Visual Function. Endocrine, 73, 407-415. https://doi.org/10.1007/s12020-021-02713-1

[16] Gerges, M.M., Rumalla, K., Godil, S.S., Younus, I. and Elshamy, W., Dobri, G.A., Kacker, A. and Tabaee, A. (2021) Long-Term Outcomes after Endoscopic Endonasal Surgery for Nonfunctioning Pituitary Macroadenomas. Journal of Neurosurgery, 134, 535-546. https://doi.org/10.3171/2019.11.JNS192457 